\title{
Plasticidade fenotípica da mamoneira precoce sob diferentes arranjos espaciais em consórcio com feijão caupi ${ }^{1}$
}

\author{
Phenotypic plasticity in the early castor bean under different spatial arrangements \\ when intercropped with cowpea
}

\author{
Tarcísio Marcos de Souza Gondim²*, Napoleão Esberad de Macêdo Beltrão ${ }^{2 \dagger}$, Walter Esfrain Pereira ${ }^{3}$, Ademar \\ Pereira de Oliveira $^{3}$ e João Luis da Silva Filho ${ }^{2}$
}

\begin{abstract}
RESUMO - O arranjo espacial facilita o manejo e proporciona a eficiência da interceptação de luz pelas folhas, numa arquitetura da ramificação com ajuste ao índice de área foliar e incremento da rentabilidade da cultura. Objetivou-se com o presente trabalho, caracterizar o comportamento morfofisiológico da mamoneira cv. BRS Energia, consorciada com feijão caupi cv. Marataoã, sob diferentes arranjos espaciais. O experimento foi conduzido na Estação Experimental da Embrapa Algodão, em Missão Velha, CE, com adubação (55-40-20). O delineamento experimental foi o de blocos casualizados, em esquema fatorial $2^{3}$ x 3 . A combinação dos fatores, dois espaçamentos entre as linhas (EL de 1,5 e 1,0 m) e entre as plantas de mamoneira (DM de 0,5 e 1,0 m) e duas densidades de feijão caupi (DC de 0,20 m, com duas, ou uma planta cova ${ }^{-1}$, a cada $0,20 \mathrm{~m}$ ), constituiu os tratamentos primários, que foram distribuídos nas parcelas e os três tipos de ramificação (Ramo do racemo primário, do secundário e do terciário), distribuídos nas subparcelas, representaram o tratamento secundário. O crescimento da mamoneira se ajusta aos diferentes arranjos de espaçamentos compensados pela plasticidade morfológica da cultura, que apresenta ângulo de menor grau $(54,30)$ nos ramos dos racemos primários e ângulos mais abertos para os ramos dos racemos secundários $(62,17)$ e terciários $(65,71)$. O EL e as DM e DC interagiram para a plasticidade da mamoneira em seu crescimento. O ângulo da ramificação aumenta com a ordem e a altura dos racemos na planta, influenciado pela densidade do cultivo.
\end{abstract}

Palavras-chave: Ricinus communis. Vigna unguiculata. Espaçamento. Ramificação.

\begin{abstract}
Spatial arrangement facilitates handling and provides efficiency in light interception by the leaves, in a branching architecture adjusted to the leaf-area index and an increased profitability of the crop. The objective of the present study was to characterise the morphological and physiological behavior of the castor bean cv. BRS Energy when intercropped with cowpea cv. Marataoã, under different spatial arrangements. The experiment was conducted at the Experimental Station of Embrapa Algodão in Missão Velha, Ceará, using fertilizer (55-40-20). The experimental design was of randomised blocks in a $2^{3} \times 3$ factorial scheme. A factor combination of two spacings between rows (EL 1.5 and $1.0 \mathrm{~m}$ ) and between castor bean plants (DM 0.5 and $1.0 \mathrm{~m}$ ), and two densities of cowpea (DC $0,20 \mathrm{~m}$, with one or two plants per hole every $0.20 \mathrm{~m}$ ), made up the primary treatments which were distributed across the plots, with the three branching types (branches of the primary, secondary and tertiary racemes) distributed across the subplots, representing the secondary treatment. The growth of the castor bean adjusts itself to the different spacings, offset by the morphological plasticity of the crop, which presents an angle of lesser degree (54.30) in the branches of the primary racemes, and more open angles in the branches of the secondary (62.17) and tertiary (65.71) racemes. The EL with the DM and DC all interacted to produce the plasticity of the castor bean during growth. The branching angle increases with the order and height of the racemes on the plant, being influenced by crop density.
\end{abstract}

Key words: Ricinus communis. Vigna unguiculata. Spacing. Branching angle.

\footnotetext{
*Autor para correspondência

${ }^{1}$ Recebido para publicação em 01/10/2012; aprovado em 11/10/2013

Trabalho extraído de parte da Tese do primeiro autor apresentada ao Programa de Pós-Graduação em Agronomia da Universidade Federal da Paraíba (CCA/UFPB), Campus II, Areia PB, pesquisa apoiada pela Embrapa Algodão - Bolsa de estudo CLT/empregado

${ }^{2}$ Embrapa Algodão, Caixa Postal 174, Campina Grande-PB, Brasil, 58.107-720, tarcisio.gondim@embrapa.br, joao.silva-filho@embrapa.br,

†in memoriam

${ }^{3}$ Departamento de Fitotecnia e Ciências Ambientais, Centro de Ciências Agrárias/CCA/UFPB, Areia-PB, Brasil, 58.397-000, wep@ cca.ufpb.br, ademar@cca.ufpb.br
} 


\section{INTRODUÇÃO}

A capacidade de adaptação e aclimatação ao estresse ambiental resulta de eventos integrados que ocorrem em todos os níveis de organização, desde o anatômico e morfológico até o celular, bioquímico e molecular (TAIZ; ZEIGER, 2004). Essas alterações que modificam a estrutura das folhas em resposta a diferentes níveis de luz, classificam as espécies quanto ao potencial de aclimatação (LARCHER, 2000) e favorecem o ajustamento de ramificações e folhas, em função do arranjo espacial de plantio.

A plasticidade é definida como variação na expressão fenotípica de um genótipo que ocorre em resposta a condições especiais e que aumenta a capacidade do indivíduo de sobreviver e reproduzir sob essas condições (BOSCHILIA; THOMAZ; PIANA, 2006). Os dados de plasticidade oferecem uma visão mais completa e complexa do desenvolvimento e revela que as populações podem apresentar diferentes padrões individuais e variada capacidade de resposta adaptativa ambientais, que incluem alongamento de hastes, suprimida ramificação e reprodução antecipada (SULTAN, 2003), produção (CHAVAN; PUJARI; LOKESHA, 2005; CORRÊA; TÁVORA; PITOMBEIRA, 2006) e qualidade do produto.

Quando as plantas crescem em populações, são morfológica e funcionalmente diferentes de plantas que crescem isoladas (BIANCHI; FLECK; DILLENBURG, 2006). Para estes autores, a plasticidade, como ajustamento, é em parte promovida por mecanismos que utilizam informações da luminosidade do dossel, traduzida por fotorreceptores específicos, que estimulam modificações morfológicas e fisiológicas em adaptação a densidades populacionais, por exemplo.

A simples técnica de combinar o intervalo compreendido entre duas fileiras de semeadura (chamado espaçamento) e a distância entre plantas de mamoneira na linha (denominada de densidade) facilita as atividades de manejo (SEVERINO et al., 2006b). O espaçamento e a densidade definem o arranjo de plantas e a população, ou número de plantas por unidade de área, que otimizam a eficiência da interceptação de luz pelas folhas, numa arquitetura da ramificação ao ajuste do índice de área foliar e incremento da produtividade da cultura.

A mamoneira é considerada uma espécie perene, mas a tecnologia de produção a utiliza como cultura anual. Naturalmente ela é multirramificada e, ao longo de seu ciclo, ramos primários dão origem a ramos secundários e assim sucessivamente (WEISS, 2000).
No crescimento da mamoneira o caule é encerrado com o surgimento da primeira inflorescência. O crescimento produtivo da planta é continuado com a emissão do ramo lateral, formado a partir da axila da última folha, logo abaixo do primeiro racemo e que se repete com o desenvolvimento de novas inflorescências, num crescimento simpodial (SAVY FILHO, 2005). Cada ramo vai terminar com um racemo em que a produção se ajusta às condições climáticas.

A resposta sobre a plasticidade da mamoneira para ajuste da ramificação em diferentes arranjos espaciais é condição necessária para a tecnologia de produção. O estreitamento do ângulo para ajuste da ramificação em função do arranjo espacial pode favorecer o manejo da cultura e a mecanização da colheita. Assim, foi objetivo deste trabalho avaliar a plasticidade fenotípica da mamoneira de ciclo precoce em diferentes arranjos de espaçamento no cultivo consorciado com feijão caupi.

\section{MATERIAL E MÉTODOS}

A pesquisa foi realizada em 2009, sob condições de sequeiro, em área da Estação Experimental da Embrapa Algodão, município de Missão Velha, CE, microrregião do Cariri cearense, nas coordenadas geográficas: latitude $07^{\circ} 13^{\prime} 13^{\prime \prime} \mathrm{S}$, longitude $39^{\circ} 10^{\prime} 21^{\prime \prime}$ WGr e altitude de aproximadamente $400 \mathrm{~m}$. A avaliação da plasticidade fenotípica da mamona Ricinus communis cultivar BRS Energia, considerada de ciclo precoce de produção ( $\leq 150$ dias após a emergência, DAE), foi realizada em sistema de consórcio com feijão caupi Vigna unguiculata cultivar BRS Marataoã (ciclo de 70 a 75 DAE).

O trabalho foi conduzido no período de 02/02/2009 a 15/08/2009, em condições de sequeiro e de acordo com as recomendações de plantio do zoneamento agrícola da mamona para o Estado do Ceará (AMARAL; SILVA, 2007).

A área experimental apresentava relevo com declividade de $3-12 \%$, classificado como relevo suave ondulado a ondulado e distribuição de curvas de nível para controle da erosão que também orientaram a preparação da área e o sentido do plantio para conservação do solo.

Na localidade, as condições edáficas foram representadas por um solo enquadrado na nova classificação como Neossolo Flúvico, de textura francoarenosa. Amostras de solo foram coletadas (camada 0 a $20 \mathrm{~cm}$ ) para análise de fertilidade, que apresentou $\mathrm{pH}=5,6$, teores médios de fósforo $\left(12,28 \mathrm{mg} \mathrm{dm}^{-3}\right)$, potássio 
(61,54 $\left.\mathrm{mg} \mathrm{dm}^{-3}\right)$, cálcio $\left(2,05 \mathrm{cmol}_{\mathrm{c}} \mathrm{dm}^{-3}\right)$ e de magnésio

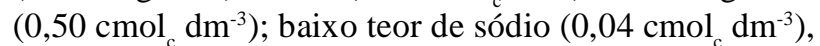
baixa acidez potencial $\left(\mathrm{H}^{+}+\mathrm{Al}^{+3} 1,65 \mathrm{cmol}_{\mathrm{c}} \mathrm{dm}^{-3}\right)$ e teores muito baixo de alumínio $\left(\mathrm{Al}^{+3}=0,10 \mathrm{cmol}_{\mathrm{c}} \mathrm{dm}^{-3}\right) \mathrm{e}$ de matéria orgânica $\left(4,40 \mathrm{~g} \mathrm{~kg}^{-1}\right)$.

A área experimental foi preparada com uma aração e duas gradagens. A adubação (55-40-20 $\left.\mathrm{kg} \mathrm{ha}^{-1}\right)$, direcionada apenas para a mamona, foi baseada na análise de solo e aplicada à cultura, com o parcelamento do nitrogênio. Os fertilizantes utilizados foram o sulfato de amônio, fosfato monoamônico (MAP) e cloreto de potássio como fonte dos nutrientes NPK, respectivamente. A cultura foi mantida livre de competição, por meio de capinas manuais em toda área experimental.

Em condições de sequeiro, a precipitação pluvial total ao longo de todo o experimento foi de $930 \mathrm{~mm}$. As variações da precipitação pluvial e da temperatura da área experimental podem ser observadas na Figura 1.

O delineamento experimental foi o de blocos casualizados, em esquema fatorial $2^{3} \times 3$. A combinação dos fatores, dois espaçamentos entre as linhas (EL de 1,5 e $1,0 \mathrm{~m}$ ) e entre as plantas de mamoneira (DM de 0,5 e $1,0 \mathrm{~m}$ ) e duas densidades de feijão caupi (DC de $0,20 \mathrm{~m}$, com duas, ou uma planta $\operatorname{cova}^{-1}$, a cada $0,20 \mathrm{~m})$, constituiu os tratamentos primários, que foram distribuídos nas parcelas e os três tipos de ramificação (ramo do racemo primário, do secundário e do terciário) (Figura 2) distribuídos nas subparcelas, representaram o tratamento secundário.
Figura 2 - (A) Desenho esquemático da parte aérea da mamoneira com identificação da sequência do desenvolvimento de ramos e racemos (B) Utilização de um transferidor escolar de $360^{\circ}$ na leitura do ângulo formado pelo ramo primário de mamoneira cv BRS Energia

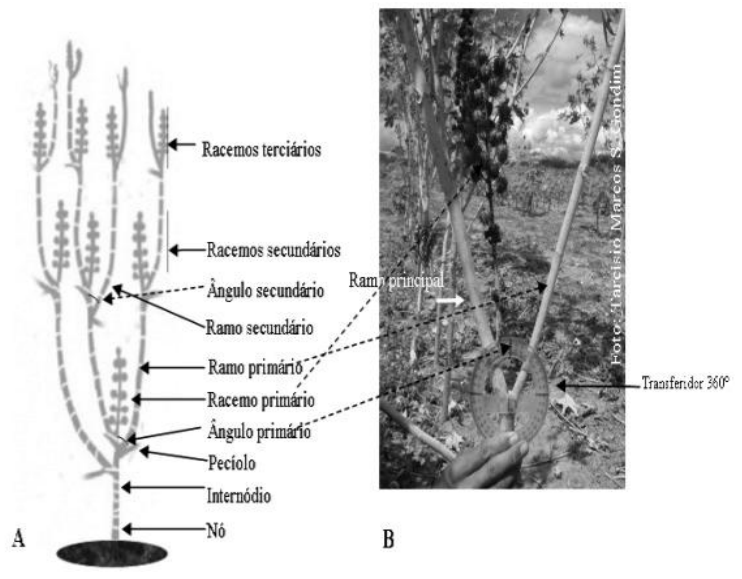

Fonte: WEISS (2000), adaptado

A parcela de $6 \mathrm{~m} \times 9 \mathrm{~m}$ apresentou área útil composta por duas fileiras centrais, cujo número de plantas foi variável de acordo com o arranjo do espaçamento do tratamento em estudo. Neste estudo foi avaliada apenas a resposta da mamoneira por meio das variáveis: ângulo dos ramos, comprimento dos entrenós até a ramificação do primeiro racemo, do segundo e do terceiro racemo e a altura do racemo

Figura 1 - Variação mensal da precipitação pluvial (Precip) e das médias de temperaturas máximas (Tmáx) e mínimas (Tmín) ocorridas nos meses de janeiro a agosto de 2009, na Estação Experimental da Embrapa em Missão Velha, CE

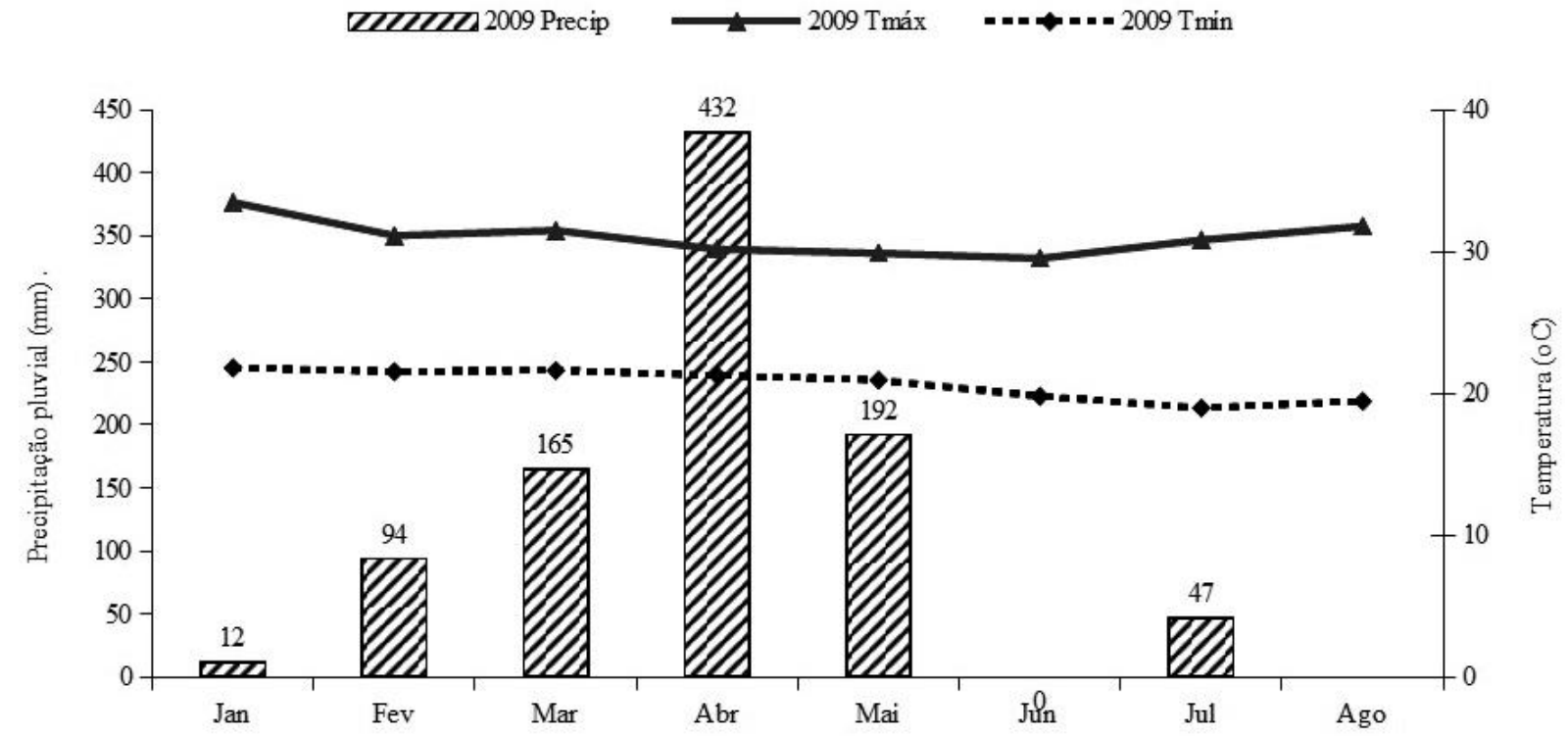

Fonte: GONDIM (2011) 
primário (corresponde à altura do caule), do secundário e terciário e da planta.

Os dados obtidos foram submetidos à análise de variância utilizando-se o teste $\mathrm{F}$ a $5 \%$ e as médias comparadas pelo teste de Tukey a 5\%. Para a comparação de médias dentro do experimento com subparcela, foram utilizadas as recomendações de SANTOS et al. (2008), conforme a significância da interação e a possibilidade de se comparar duas médias dos níveis do fator principal, duas médias dos níveis do fator secundário, médias dos níveis do fator secundário dentro de cada nível do fator principal ou de qualquer combinação entre níveis de dois fatores.

\section{RESULTADOS E DISCUSSÃO}

Os resumos das análises de variância relativos à avaliação das variáveis de crescimento da cultura da mamoneira são apresentados na Tabela 1 .

Avariávelângulo de ramos foi influenciada pela ordem da ramificação $(\mathrm{P}<0,01)$. Quando realizado o desdobramento do efeito significativo $(\mathrm{P}<0,01)$ de ramos dentro do fator densidade de mamoneira (DM) (Figura 3), observa-se que o comportamento dos ângulos cresceu conforme a ordem dos racemos primários, secundários e terciários, tanto na densidade de mamoneira $0,5 \mathrm{~m}$, quanto na DM de $1,0 \mathrm{~m}$.

Tabela 1 - Resumo das análises de variância pelos quadrados médios, para os componentes de crescimento morfológico do ângulo dos racemos (ANG), do comprimento médio de entrenós (CME) e altura de ramificação (ALTr) e de plantas (ALTp) de mamoneira cv. BRS Energia cultivada em diferentes arranjos espaciais, consorciada com feijão caupi cv. BRS Marataoã, nas condições de sequeiro no Cariri cearense

\begin{tabular}{|c|c|c|c|c|c|}
\hline \multirow{2}{*}{ Fontes de variação } & \multirow{2}{*}{ GL } & \multicolumn{4}{|c|}{ QUADRADO MÉDIO } \\
\hline & & ANG & $\mathrm{CME}$ & ALTr & ALTp \\
\hline Blocos & 3 & $0,805^{\mathrm{ns}}$ & $0,509^{\text {ns }}$ & $77,241^{\mathrm{ns}}$ & $509,913^{\mathrm{ns}}$ \\
\hline EL & 1 & $3,682^{\mathrm{ns}}$ & $5,801 *$ & $696,065^{\mathrm{ns}}$ & $107,527^{\mathrm{ns}}$ \\
\hline DM & 1 & $15,360^{\mathrm{ns}}$ & $12,760 * *$ & $4960,81 * *$ & $1969,282^{\mathrm{ns}}$ \\
\hline DC & 1 & $47,040 *$ & $0,010^{\mathrm{ns}}$ & $310,680^{\mathrm{ns}}$ & $653,127^{\mathrm{ns}}$ \\
\hline EL x DM & 1 & $1,500^{\mathrm{ns}}$ & $0,602^{\mathrm{ns}}$ & $316,463^{\mathrm{ns}}$ & $3283,020^{\mathrm{ns}}$ \\
\hline EL $x$ DC & 1 & $2,940^{\mathrm{ns}}$ & $0,807^{\mathrm{ns}}$ & $483,753^{\mathrm{ns}}$ & $776,344^{\mathrm{ns}}$ \\
\hline DM x DC & 1 & $21,282^{\mathrm{ns}}$ & $1,870^{\mathrm{ns}}$ & $763,317^{\mathrm{ns}}$ & $2977,054^{\mathrm{ns}}$ \\
\hline EL $x$ DM $x$ DC & 1 & $14,415^{\mathrm{ns}}$ & $1,127^{\mathrm{ns}}$ & $325,238^{\mathrm{ns}}$ & $2002,027^{\mathrm{ns}}$ \\
\hline Erro (a) & 21 & 7,8834 & 1,223 & 222,523 & 799,328 \\
\hline Parcelas & $(31)$ & & & & \\
\hline Ramo & 2 & $1090,7 * *$ & $46,033 * *$ & $71653,2 * *$ & $69056,36 * *$ \\
\hline EL x Ramo & 2 & $4,229^{\mathrm{ns}}$ & $0,286^{\mathrm{ns}}$ & $276,91 * *$ & $339,714^{\mathrm{ns}}$ \\
\hline DM x Ramo & 2 & $25,257 * *$ & $0,766^{*}$ & $26,153^{\text {ns }}$ & $474,661 *$ \\
\hline DC x Ramo & 2 & $9,801^{\mathrm{ns}}$ & $0,228^{\mathrm{ns}}$ & $3,641^{\mathrm{ns}}$ & 241,829 \\
\hline EL x DM x Ramo & 2 & $7,296^{\mathrm{ns}}$ & $0,136^{\mathrm{ns}}$ & $177,696 *$ & $563,479 *$ \\
\hline EL x DC x Ramo & 2 & $0,435^{\mathrm{ns}}$ & $0,261^{\mathrm{ns}}$ & $223,458 *$ & $206,262^{\mathrm{ns}}$ \\
\hline DM x DC x Ramo & 2 & $8,253^{\mathrm{ns}}$ & $0,327^{\mathrm{ns}}$ & $344,443 * *$ & $62,888^{\mathrm{ns}}$ \\
\hline EL x DM x DC x Ramo & 2 & $4,727^{\mathrm{ns}}$ & $0,127^{\mathrm{ns}}$ & $49,746^{\mathrm{ns}}$ & $1,335^{\mathrm{ns}}$ \\
\hline Resíduo & 48 & 4,765 & 0,151 & 52,864 & 140,112 \\
\hline TOTAL & 95 & & & & \\
\hline Coeficiente de variação CVa (\%) & & 4,62 & 15,78 & 12,29 & 15,78 \\
\hline Coeficiente de variação CVb (\%) & & 3,59 & 5,55 & 5,99 & 6,61 \\
\hline Média geral & & $60,73^{\circ}$ & $7,01 \mathrm{~cm}$ & $121,34 \mathrm{~cm}$ & $179,14 \mathrm{~cm}$ \\
\hline
\end{tabular}

GL- Grau de liberdade; ${ }^{\text {ns }}$ - não significativo; $* *$ e * significativo a 1 e a $5 \%$, respectivamente, pelo teste F; EL - Espaçamento entre linha de mamona $(1,5 \mathrm{~m}$ e $1,0 \mathrm{~m})$; DM - Distância entre plantas de mamoneira $(0,5 \mathrm{~m}$ e $1,0 \mathrm{~m})$, com uma planta cova ${ }^{-1}$; DC - Distância entre plantas de feijão caupi $\left(\mathrm{DC}=0,1\right.$ corresponde a duas plantas cova ${ }^{-1}$, a cada $0,2 \mathrm{~m} ; \mathrm{DC}=0,2$, a uma planta cova ${ }^{-1}$, a cada $0,2 \mathrm{~m}$ ); Ramo - tipo de ramificação correspondente aos ramos dos racemos primários, secundários e terciários. Fonte: GONDIM (2011) 
Figura 3 - Ângulo dos ramos primário, secundário e terciário da mamoneira cv. BRS Energia em função do tipo de ramificação (Ramo) e da densidade da semeadura da mamoneira consorciada com feijão caupi cv. BRS Marataoã, nas condições de sequeiro do Cariri cearense

口 Ramo primário

Ramo secundário

口 Ramo terciário

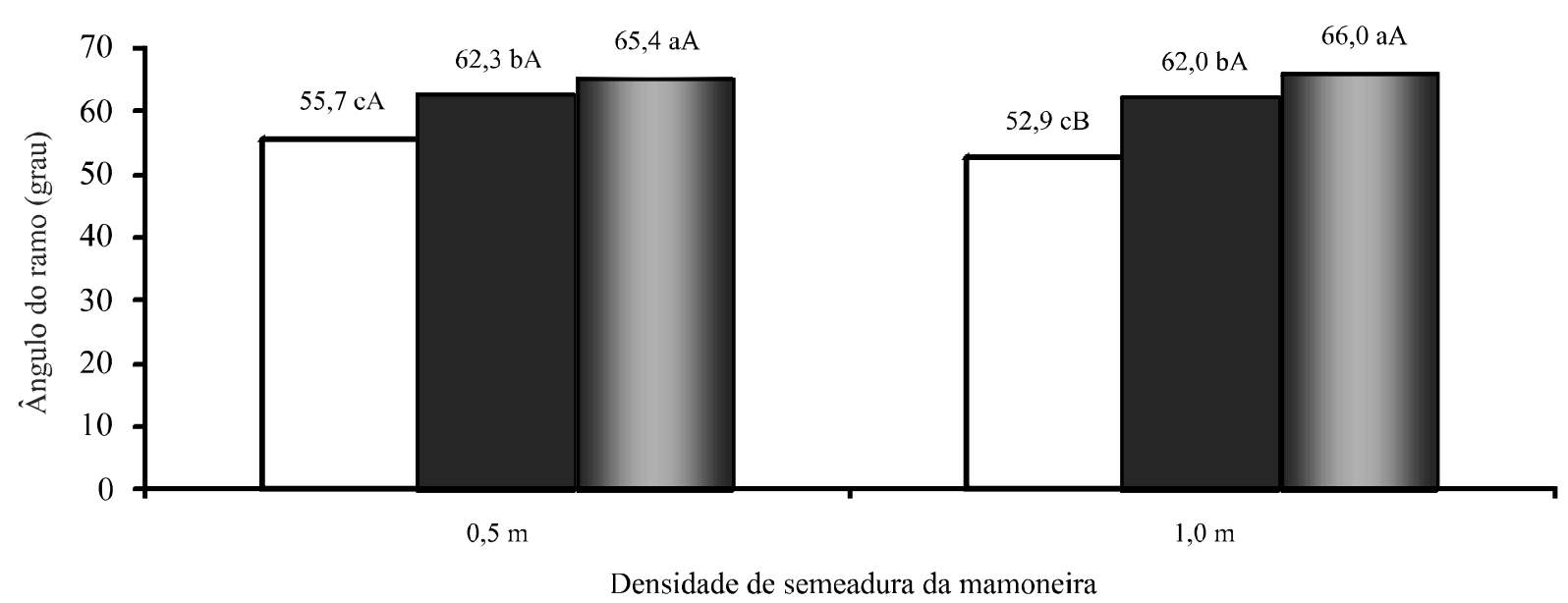

a, b, c, A, B - Médias seguidas de mesmas letras minúsculas entre diferentes tipos de ramos dentro da mesma densidade de semeadura da mamoneira, espaçamento entre plantas na fileira, e maiúsculas entre o mesmo tipo de ramo entre densidades de semeadura, não diferem pelo teste de Tukey $(\mathrm{P}>0,05)$. Diferença mínima significativa $\left(\mathrm{DMS}_{\mathrm{ramo}}\right): 1,87$ graus, DMS : 1,55 graus. Fonte: GONDIM (2011)

Com este comportamento, acredita-se que a mamoneira se ajusta, em primeiro momento, ao arranjo espacial e, posteriormente, aos espaços da copa da própria planta e também aos do dossel de plantas vizinhas, para distribuição de ramos, folhas e racemos, numa característica morfogenética do crescimento simpodial.

Os ângulos dos ramos oriundos imediatamente abaixo dos racemos primários foram, pelo teste de Tukey a 5\%, significativamente menores que os ângulos dos ramos dos racemos secundários e esses menores que o dos terciários. Em relação à densidade de semeadura da mamoneira, a DM de 0,5 m apresentou ângulo do ramo primário $\left(55,7^{\circ}\right)$ superior em $5 \%$ ao mesmo ângulo observado nas mamoneiras da DM de 1,0 m.

Em trabalho realizado com outra euforbiácea, a mandioca (Manihot esculenta Crantz), Irolivea et al. (1998) verificaram que os menores espaçamentos reduziram o ângulo de ramificação das cultivares ramificadas, mas proporcionaram aumento do rendimento das cultivares que não se ramificavam.

Os ramos primários da mamoneira emitidos logo após a emissão da inflorescência primária na qual termina o caule principal dão suporte ao desenvolvimento das ramificações secundárias, terciárias e demais ramificações ao longo do ciclo (WEISS, 2000), em que cada ramo encerra uma inflorescência tipo racemo. A plasticidade da ramificação primária, quanto ao menor ângulo observado na presente avaliação pode, na presença de outras variáveis de crescimento, a seguir analisadas, constituir a base de um ajuste da mamoneira no arranjo de plantio desta oleaginosa, em cultivos manuais ou mecanizados.

$\mathrm{Na}$ Tabela 1 se observa efeito significativo para a variável comprimento médio de entrenós (CME) em função do espaçamento entre linha de mamona $(\mathrm{EL})(\mathrm{P}<0,05)$, distância entre plantas de mamona (DM) $(\mathrm{P}<0,01)$, tipos de ramificação (Ramo) $(\mathrm{P}<0,01)$ e para a interação DM x Ramo $(\mathrm{P}<0,05)$. No procedimento do confronto de médias, considerando-se a significância da interação DM x Ramo, observa-se que no tratamento secundário, dentro de cada DM, o maior CME ocorreu para os ramos terciários (Figura 4).

Considerado característica morfológica do crescimento da mamoneira associada à precocidade, o número de nós na haste principal varia de seis a doze (WEISS, 2000), mas o comprimento dos entrenós pode ser influenciado, entre outros fatores, pelo espaçamento do plantio. Em arranjo populacional mais adensado, Carvalho et al. (2010) encontraram plantas com maior altura mas também sua contribuição para a maior produtividade da cultura.

O comprimento médio dos entrenós (CME) de ramos ligados aos racemos terciários da mamoneira cv. BRS Energia superou o CME do seu caule em 34,0 e 50,0\%, respectivamente para a densidade DM de 0,5 $\mathrm{m}$ e DM de $1,0 \mathrm{~m}$. A DM de $0,5 \mathrm{~m}$ aumentou o CME em cerca de $15 \%$ em relação a $\mathrm{DM}$ de $1,0 \mathrm{~m}$, devido, provavelmente, à competição por luz em maior evidência neste espaçamento entre plantas de mamoneira cv. BRS Energia. 
Figura 4 - Comprimento médio de entrenós (CME) de mamoneira cv. BRS Energia em função do tipo de ramificação (ramo primário, secundário e terciário) e da densidade de semeio de mamoneira (DM) consorciada com feijão caupi cv. BRS Marataoã, nas condições de sequeiro no Cariri cearense

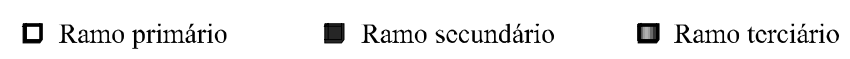

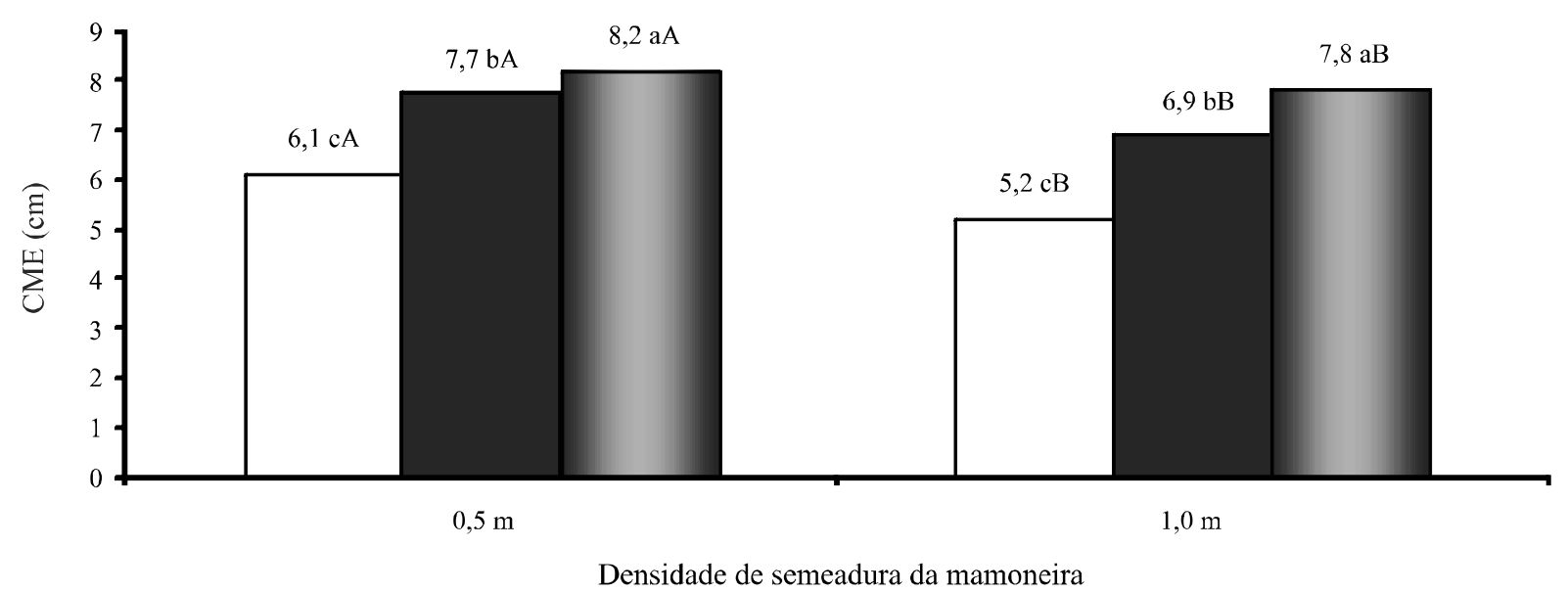

a, b, c, A, B - Médias seguidas de mesmas letras minúsculas entre diferentes tipos de ramos dentro da DM e maiúsculas entre o mesmo tipo de ramo dentro da DM, não diferem pelo teste de Tukey $(\mathrm{P}>0,05)$. Diferença mínima significativa $\left(\mathrm{DMS}_{\mathrm{ramo}}\right)$ : $0,33 \mathrm{~cm}, \mathrm{DMS} \mathrm{DM}_{\mathrm{DM}}: 0,27 \mathrm{~cm}$. Fonte: GONDIM $(2011)$

A maior altura de inserção do primeiro racemo, que influencia o comprimento dos entrenós do caule observado nos menores espaçamentos de cultivo de mamoneira cv. Guarani foi atribuída ao possível estiolamento provocado pela competição por luz de forma intraespecífica (BIZINOTO et al., 2010). A atenuação da radiação na cobertura vegetal depende principalmente da densidade da folhagem, do arranjo das folhas no interior da vegetação e do ângulo existente entre a folha e a radiação incidente (LARCHER, 2000).

De acordo com a análise de variância para altura de racemos (ALTr), observa-se que houve influência das fontes de variação densidade de mamona (DM) e tipo de ramificação (Ramo), de forma altamente significativa $(\mathrm{P}<0,01)$, para os fatores isolados ou em interação com o espaçamento entre linhas de mamona (EL) (EL x Ramo) e com densidade do feijão caupi consorciado (DC) (DM x DC x Ramo) (Tabela 1). As interações EL x DM x Ramo e EL x DC x Ramo apresentaram efeito significativo a 5\%. Para os demais fatores e interações da análise não se verificou efeito significativo $(\mathrm{P}>0,05)$, sobre a altura dos racemos primários, secundários e terciários.

A morfologia de crescimento simpodial da mamoneira com a ordem dos racemos, sempre crescente é constatada nas Figuras 5; 6 e 7. Entretanto, os espaçamentos entre linhas (EL), densidade da mamoneira (DM) e do feijão caupi (DC) influenciaram no percentual dessa superioridade, como plasticidade da mamoneira à referida condição dos arranjos espaciais.

Ao analisar os resultados da altura dos racemos dentro de cada EL (1,5 m e 1,0 m) nota-se que os três tipos de racemo foram mais altos na DM de $0,5 \mathrm{~m}$ (população de 13.333 plantas e 20.000 plantas ha ${ }^{-1}$ ), do que na DM

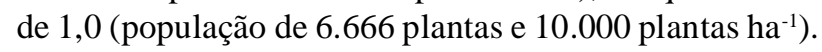
A maior influência da DM foi sobre o racemo primário, quando elevou a altura dos mesmos em 20,77 e 17,16\%, respectivamente, nas DM de 0,5 m e de 1,0 m (Figura 5). Verifica-se também que a altura dos racemos, dentro das mesmas densidades (DM de 0,5 m, ou 1,0 m), em cada espaçamento (EL) não afetou o ponto de inserção do racemo primário. Por outro lado, sua influência foi verificada na altura dos racemos terciários e, mais incisivamente, na dos secundários, com aumento de 7,96 e $11,51 \%$ em relação à altura dos referidos racemos no espaçamento mais largo (EL de 1,5 m).

Em densidade do feijão caupi (DC de 0,1 e 0,2), apenas a altura dos racemos terciários da mamoneira apresentou plasticidade (Figura 6). A interferência da DC de $0,1 \mathrm{~m}$ (10 plantas $\left.\mathrm{m}^{-1}\right)$, no espaçamento EL de 1,0 m, superou a altura desses racemos em $13,8 \mathrm{~cm}(8,53 \%)$, na comparação com a DC de 0,2 (5 plantas $\mathrm{m}^{-1}$, a cada $\left.0,20 \mathrm{~m}\right)$. Efeitos de adaptação ou funcionais, devidos possivelmente ao estiolamento (competição por luz) e, ou à fixação biológica de nitrogênio $(\mathrm{N})$ pelo feijão caupi, elevaram a altura do terceiro racemo, uma vez que a resposta não foi constatada nos dois tipos de racemo de ordem inferior. 
Figura 5 - Altura de racemos primários, secundários e terciários de mamoneira cv. BRS Energia em função do tipo de ramificação (ramo primário, secundário e terciário), do espaçamento entre linhas e da densidade de semeio da mamoneira (DM) consorciada com feijão caupi cv. BRS Marataoã, nas condições de sequeiro no Cariri cearense

- Ramo primário $\quad \square$ Ramo secundário $\quad \square$ Ramo terciário

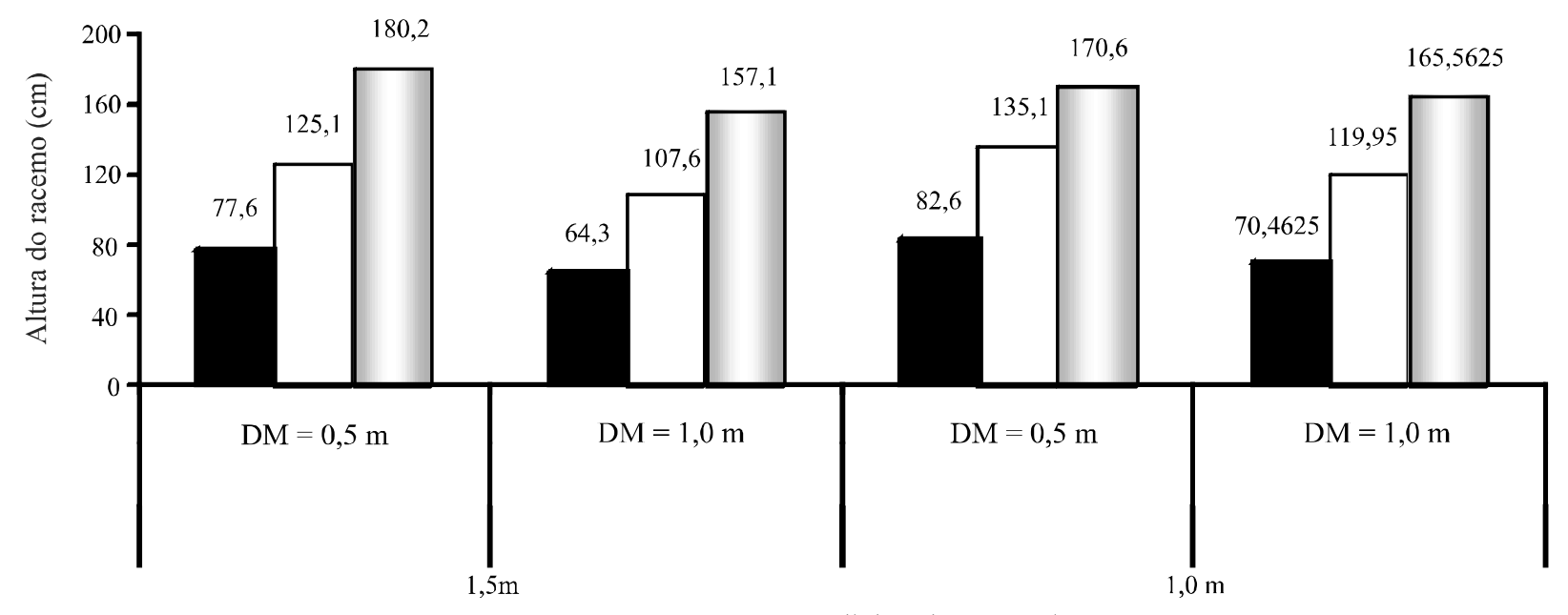

Espaçamento entre linhas de manoneira

a, b, c, A, B, $\alpha, \beta$ - Médias sobre mesmas letras minúsculas entre diferentes tipos de ramos dentro do espaçamento entre linhas de mamoneira (EL) e da densidade de mamoneira (DM); maiúsculas entre o mesmo tipo de ramo dentro do mesmo EL com diferentes DM e, mesmas letras gregas entre diferentes EL e dentro das mesmas DM não diferem pelo teste de Tukey $(\mathrm{P}>0,05)$. Diferença mínima significativa $\left(\mathrm{DMS}{ }_{\text {ramo }}\right.$ ): 8,79 cm. Fonte: GONDIM (2011)

Figura 6 - Altura de racemos primários, secundários e terciários de mamoneira cv. BRS Energia em função do tipo de ramificação (ramo primário, secundário e terciário), do espaçamento entre linhas de mamona e da densidade de semeio do feijão caupi cv. BRS Marataoã (DC- 0,2 e 0,1, correspondentes a duas plantas $\operatorname{cova}^{-1} \mathrm{e}$ a uma planta cova ${ }^{-1}$, a cada $0,20 \mathrm{~m}$, respectivamente) no consórcio, nas condições de sequeiro no Cariri cearense

- Ramo primário $\square$ Ramo secundário $\square$ Ramo terciário

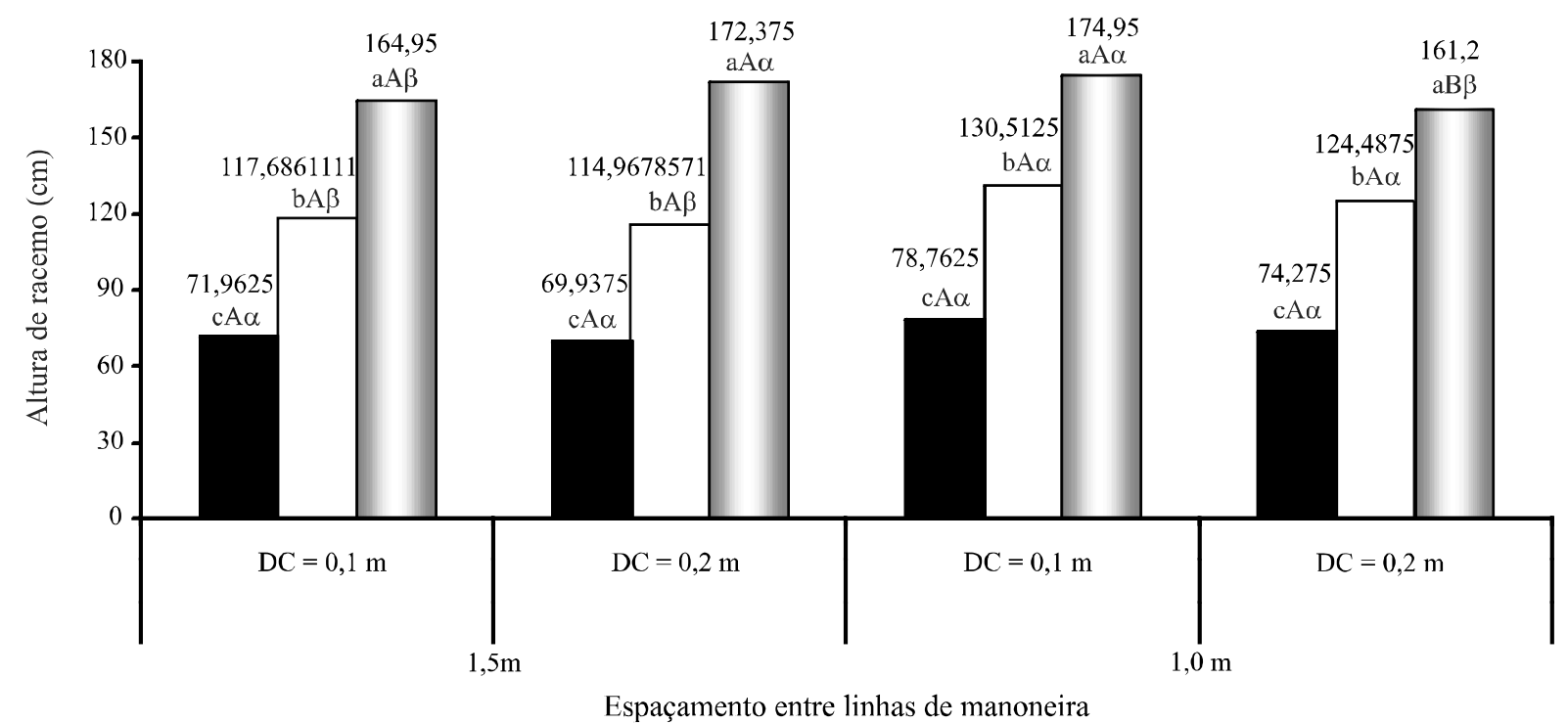

a, b, c, A, B, $\alpha, \beta$ - Médias sobre mesmas letras minúsculas entre diferentes tipos de ramos dentro do espaçamento entre linhas de mamoneira (EL) e da densidade de feijão caupi (DC); maiúsculas entre o mesmo tipo de ramo dentro do mesmo EL com diferentes DC e, mesmas letras gregas entre diferentes EL e dentro das mesmas DC não diferem pelo teste de Tukey (P > 0,05). Fonte: GONDIM (2011) 
Para essa fase do crescimento o possível $\mathrm{N}$ fixado pelas bactérias estava suprindo parte da demanda do feijão caupi, em condição também favorável à mamoneira. A distância de $50 \mathrm{~cm}$ entre fileiras das culturas consorciadas pode também ter favorecido a utilização do $\mathrm{N}$ fornecido pelo feijão caupi para a mamoneira, que respondeu na altura do racemo ou ramo de terceira ordem.

De acordo com os resultados observados na Figura 7, esta hipótese parece se confirmar quando a maior altura de racemo terciário $(183,6 \mathrm{~cm})$ também é verificada para o racemo terciário, nas densidades mais estreitas (DM de 0,5 m e DC de 0,1). Severino et al. (2006b), Bizinoto et al. (2010) e Soratto et al. (2011) mencionam que o adensamento tem maior influência na altura de inserção do primeiro cacho que na altura da planta da mamoneira, em consequência de possível estiolamento do caule, provocado pela competição por luz.

A atribuição aos efeitos de competição por luz (CARVALHO et al., 2010; SEVERINO et al., 2006a, 2006b) de forma isolada, pode ser descartada, uma vez que a variação do crescimento não foi percebida para os racemos de ordem inferior (racemos primários e secundários), em comparação com a avaliação que isolou o efeito da densidade do feijão caupi (Figuras 5 e 6). Estudos futuros podem explorar essa linha de investigação.

A altura das plantas (ALTp) de mamoneira cv. BRS Energia, foi influenciada principalmente pelos efeitos dos tratamentos testados nas subparcelas que, além de serem determinados com maior precisão que os efeitos testados nas parcelas (SANTOS et al., 2008), teve alta variação. Nas subparcelas, o tipo de ramificação apresentou efeitos significativos $(\mathrm{P}<0,01)$, bem como as interações DM x Ramo e EL x DM x Ramo $(\mathrm{P}<0,05)$ (Tabela 1). Não se constatou efeito significativo dos fatores espaçamento entre linhas de mamoneira (EL$1,5 \mathrm{~m} \mathrm{e} 1,0 \mathrm{~m}$ ), densidade de mamoneira (DM- 0,5 m e $1,0 \mathrm{~m}$ ) e densidade de feijão caupi (DC- $0,1 \mathrm{~m}$ e $0,2 \mathrm{~m}$ ) testados nas parcelas, em relação à altura das plantas, tal como para a interação entre esses fatores.

Na Figura 8, verifica-se, por meio da análise do desdobramento de "Ramo" dentro de cada nível de "EL x DM", que a altura das plantas é crescente com a ordem dos racemos e é maior quando as plantas produzem o

Figura 7 - Altura de racemos primários, secundários e terciários da mamoneira cv. BRS Energia em função do tipo de ramificação (ramo primário, secundário e terciário), da densidade de semeio da mamoneira (DM), e da densidade de feijão caupi cv. BRS Marataoã (DC de 0,2 e 0,1, correspondentes a duas plantas cova ${ }^{-1}$ e a uma planta cova ${ }^{-1}$, a cada $0,20 \mathrm{~m}$, respectivamente), em consórcio nas condições de sequeiro do Cariri cearense

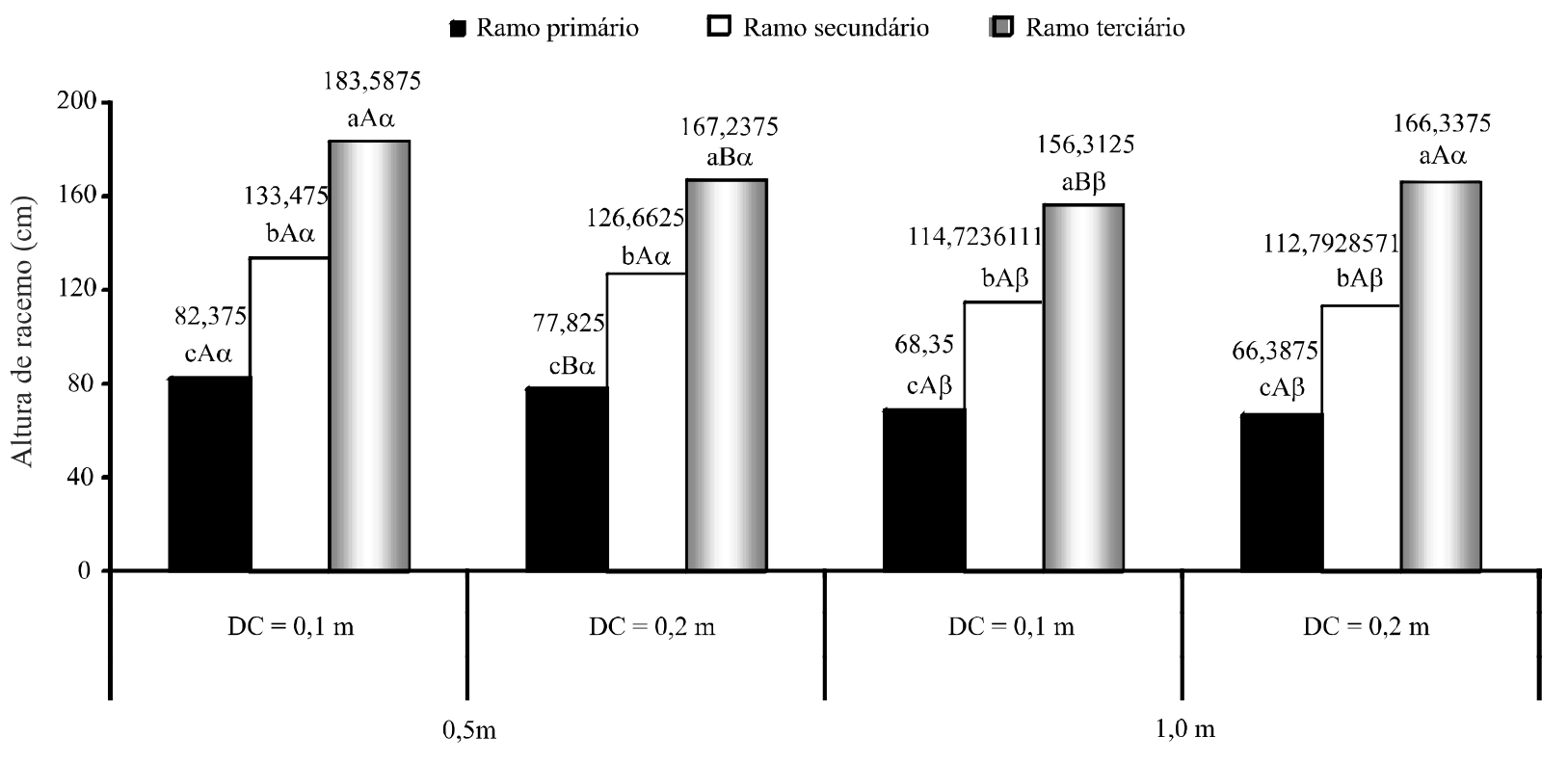

Densidade de mamoneira, espaçamento entre plantas na fileira

a, b, c, A, B, $\alpha, \beta$ - Médias sobre mesmas letras, minúsculas entre diferentes tipos de ramos dentro da densidade de mamoneira (DM) e da densidade de feijão caupi (DC); maiúsculas entre o mesmo tipo de ramo dentro da mesma DM com diferentes DC e, mesmas letras gregas entre diferentes DM e dentro das mesmas DC não diferem pelo teste de Tukey $(\mathrm{P}>0,05)$. Fonte: GONDIM (2011) 
Figura 8 - Altura de plantas de mamoneira cv. BRS Energia em função do tipo de ramificação (ramo primário, secundário e terciário), dentro do espaçamento entre linhas (EL) e da densidade de semeio da mamoneira (DM) consorciada com feijão caupi cv. BRS Marataoã, nas condições de sequeiro no Cariri cearense

- Ramo primário $\quad \square$ Ramo secundário $\quad$ Ramo terciário

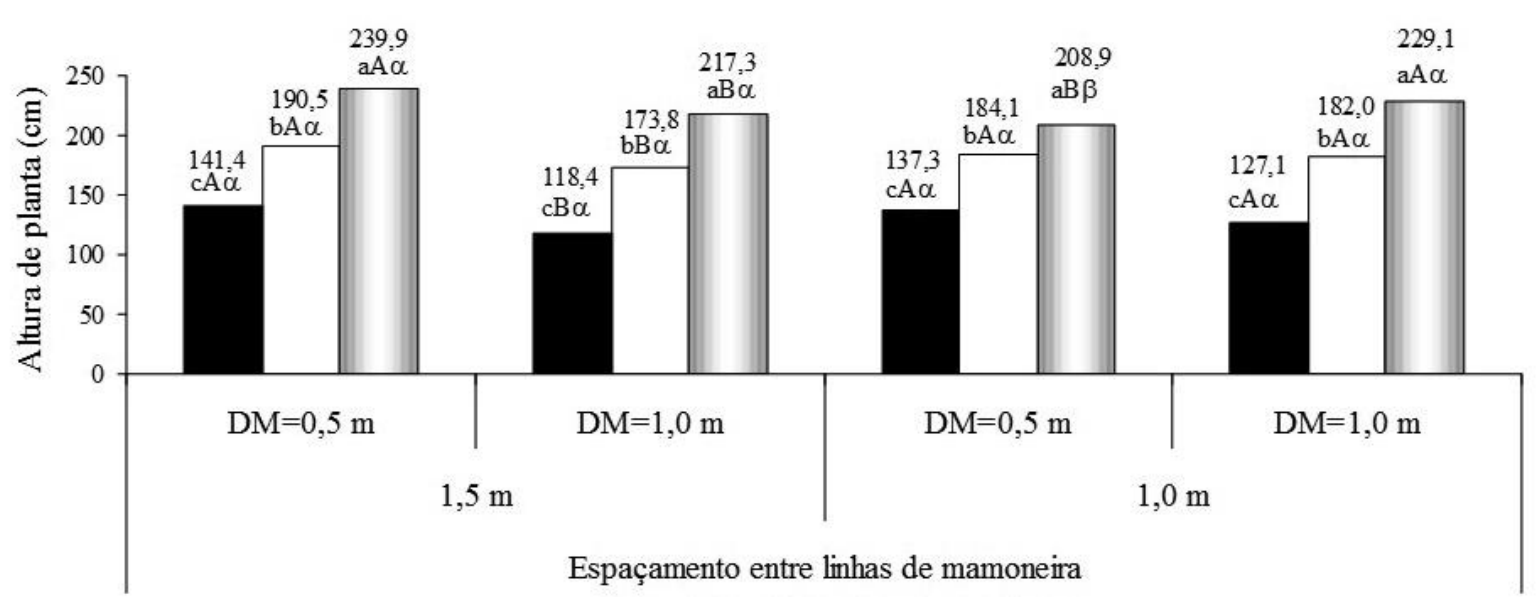

a, b, c, A, B, $\alpha, \beta$ - Médias sobre mesmas letras minúsculas entre diferentes tipos de ramo dentro do espaçamento entre linhas de mamoneira (EL) e da densidade de mamoneira (DM); maiúsculas entre o mesmo tipo de ramo dentro do mesmo EL com diferentes DM e mesmas letras gregas entre diferentes EL e dentro das mesmas DM, não diferem pelo teste de Tukey (P > 0,05). Diferença mínima significativa (DMS ${ }_{\text {ramo }}$ ): 8,79 cm. Fonte: GONDIM (2011)

racemo de terceira ordem. Subsequentemente, as plantas com racemos secundários são mais altas quando as mesmas só apresentam o primeiro racemo, em perfeito crescimento simpodial (SAVY FILHO, 2005).

No espaçamento (EL- 1,5 m), o crescimento da mamoneira sob a DM- 0,5 m teve altura superior de plantas, em percentuais de quase 20,0; 10,0 e $10,0 \%$ em relação à altura das plantas com racemos primários, secundários ou terciários, na DM- 1,0 m, respectivamente (Figura 8).

Quando as plantas cresceram no EL de 1,0 m, a altura $(229,1 \mathrm{~cm})$ foi maior $(9,66 \%)$ na fase fenológica do racemo terciário em comparação à densidade $(\mathrm{DM}=$ $0,5 \mathrm{~m}$ e $1,0 \mathrm{~m}$ ). Ocorreu semelhança do comportamento da altura de planta com a altura do racemo, quando EL de 1,5 m e DM de 0,5 m compuseram o arranjo espacial. $\mathrm{O}$ ajuste de crescimento representado pela altura de mamoneira, como plasticidade ao arranjo espacial, também foi observado por Severino et al. (2006a), ao constatarem maiores alturas das plantas nos espaçamentos mais largos, em menores populações de plantas.

O sucesso do cultivo da mamoneira depende da capacidade produtiva e da estabilidade de produção das cultivares, tal como também da segurança dos sistemas de produção (KOUTROUBAS; PAPAKOSTA; DOITSINIS, 1999; SORATTO et al., 2011). No entanto, pensando na plasticidade da cultura em sistemas de cultivo, esses autores verificaram que as características morfológicas da altura de inserção do primeiro racemo e da altura da mamoneira foram influenciadas tanto pelo genótipo quanto pelo local, mas a variável altura dos racemos tem maior variação nas diferentes condições.

No aspecto da colheita da mamoneira, a altura da planta é uma das características morfológicas mais relevantes que afetam esta operação, quer seja manual ou mecânica. A altura de até $2,0 \mathrm{~m}$ e caules finos tem sido reportados como responsável pela facilidade da colheita (FERREIRA et al., 2009; LAURETI; MARRAS, 1995; LOPES et al., 2008). Neste sentido, o arranjo espacial com EL de 1,0 e DM de 0,5 m foi o que teve altura mais próxima dessa referência. A altura das plantas com racemo terciário dos demais arranjos supera os 2,0 $\mathrm{m}$ referenciados, o que dificulta a colheita, mas não impossibilita sua execução.

$\mathrm{O}$ investimento inicial pronunciado no alongamento vertical do caule e uma reduzida ramificação da parte aérea são considerados respostas fenotípicas adaptativas. Tais alterações morfológicas e fisiológicas, cujas expressões se apresentam temporariamente descontínuas, são interpretadas como ajustes para uma absorção mais eficiente de luz e de economia de recursos sob condições de autossombreamento e contribuem para a tolerância ao sombreamento da espécie (FRANCO; DILLENBURG, 2007; GONDIM et al., 2008). 


\section{CONCLUSÕES}

1.O espaçamento entre linhas de mamoneira cv. BRS Energia $(1,5 \mathrm{~m}$ e $1,0 \mathrm{~m})$ e o espaço entre plantas na linha da mamoneira $(0,5 \mathrm{~m}$ e $1,0 \mathrm{~m})$ e do feijão caupi $\left(0,1\right.$ e 0,2 , correspondente a duas plantas $\operatorname{cova}^{-1}$ e a uma planta $\operatorname{cova}^{-1}$, a cada $0,20 \mathrm{~m}$, respectivamente), interagiram para a plasticidade da mamoneira em seu crescimento;

2. A densidade da mamoneira interferiu no ângulo do ramo e essa plasticidade, ou adaptação, foi mais acentuada no ângulo dos ramos ligados aos racemos primários;

3. A plasticidade da mamoneira cv. BRS Energia consorciada com feijão caupi cv. BRS Marataoã permitiu o ajuste fenológico da cultura em cultivos mais adensados.

\section{REFERÊNCIAS}

AMARAL, J. A. B. do; SILVA, M. T. Zoneamento de riscos climáticos da cultura da mamoneira no Estado do Ceará, referente ao ano-safra de $2007 / 2008$. Campina Grande: Embrapa Algodão, 2007. 8 p. (Embrapa Algodão. Comunicado Técnico, 331).

BIANCHI, M. A.; FLECK, N. G.; DILLENBURG, L. R. Partição da competição por recursos do solo e radiação solar entre cultivares de soja e genótipos concorrentes. Planta Daninha, v. 24, n. 4, p. 629-639, 2006.

BIZINOTO, T. K. M. C. et al. Cultivo da mamoneira influenciada por diferentes populações de plantas. Bragantia, v. 69 , n. 2, p. 367-370, 2010.

BOSCHILIA, S. M.; THOMAZ, S. M.; PIANA, P. A. Plasticidade morfológica de Salvinia herzogii (de La Sota) em resposta à densidade populacional. Acta Scientiarum Biological Sciences, v. 28, n. 1, p. 35-39, 2006.

CARVAlHO, E. V. et al. Densidade de plantio em duas cultivares de mamona no Sul do Tocantins. Revista Ciência Agronômica, v. 41, n. 3, p. 387-392, 2010.

CHAVAN, M.; PUJARI, B. T.; LOKESHA, R. Morphological indices and yield of castor as influenced by organic and inorganic sources of nitrogen. Karnataka. Journal of Agricultural Sciences, v. 18, n. 4, p. 1075-1077, 2005.

CORRÊA, M. L. P.; TÁVORA, F. J. A. F.; PITOMBEIRA, J. B. Comportamento de cultivares de mamona em sistemas de cultivo isolados e consorciados com caupi e sorgo granífero. Revista Ciência Agronômica, v. 37, n. 2, p. 200-207, 2006.

FERREIRA, M. G. C.; MARUYAMA, W. I.; SORATTO, R. P. Avaliação de cultivares de mamona em dois arranjos de plantas no outono-inverno em Cassilândia-MS. Revista Brasileira de Oleaginosas e Fibrosas, v. 13, n. 2, p. 53-60, 2009.

FRANCO, A. M. S.; DILlENBURG, L. R. Ajustes morfológicos e fisiológicos em plantas jovens de Araucaria angustifolia (Bertol.) Kuntze em resposta ao sombreamento. Hoehnea, v. 34, n. 2, p. 135-144, 2007.

GONDIM, A. R. O. et al. Plasticidade anatômica da folha de taro cultivado sob diferentes condições de sombreamento. Bragantia [online], v. 67, n. 4, p. 1037-1045, 2008.

GONDIM, T. M. S. Arranjos espaciais e sua influência no consórcio mamoneira precoce e feijão caupi. 2011. $177 \mathrm{f}$. Tese (Doutorado em Agronomia) - Centro de Ciências Agrárias. Universidade Federal da Paraíba, Areia, 2011.

IROLIVEA, E. A. M. et al. Efeito do espaçamento entre plantas e da arquitetura varietal no comportamento vegetativo e produtivo da mandioca. Scientia Agrícola, v. 55, n. 2, p. 1998.

KOUTROUBAS, S. D., PAPAKOSTA, D. K.; DOITSINIS, A. Adaptation and yielding ability of castor plant (Ricinus communis L.) genotypes in a Mediterranean climate. European Journal of Agronomy, v. 11, n. 3-4, p. 227-237, 1999.

LARCHER, W. Ecofisiologia Vegetal. São Carlos: Rima, 2000. $531 \mathrm{p}$.

LAURETI, D.; MARRAS, G. Irrigation of castor (Ricinus communis L.) in Italy. European Journal of Agronomy, v. 4, n. 2, p. 229-235, 1995.

LOPES, F. F. de M. et al.. Crescimento inicial de genótipos de mamoneira com sementes submetidas ao envelhecimento acelerado. Revista Brasileira de Oleaginosas e Fibrosas, v. 12 , p. $69-79,2008$.

MELO, F. B.; BELTRÃO, N. E. de M.; SILVA, P. H. S. Cultivo da mamona (Ricinus communis L.) consorciada com feijão-caupi (Vigna unguiculata L. Walp.) no Semi-Árido. Teresina: Embrapa Meio-Norte, 2003, 89 p. (Embrapa Meio-Norte. Documentos, 74).

SANTOS, J. W. et al. Estatística Experimental Aplicada. 2. ed. rev. e ampl. Campina Grande: Embrapa Algodão/Universidade Federal de Campina Grande, 2008. p. 187-271.

SAVY FILHO, A. Mamona: tecnologia agrícola. Campinas: EMOPI, 2005. 105 p.

SEVERINO, L. S. et al. Otimização do espaçamento de plantio para a mamoneira cultivar BRS Nordestina. Revista Brasileira de Oleaginosas e Fibrosas, v. 10, p. 993-999, 2006a.

SEVERINO, L. S. et al. Crescimento e produtividade da mamoneira influenciada por plantio em diferentes espaçamentos entre linhas. Revista Ciência Agronômica, v. 37 , n. 1 , p. $50-54,2006$ b.

SORATTO, R. P. et al. Espaçamento e população de plantas de mamoneira de porte baixo para colheita mecanizada. Pesquisa Agropecuária Brasileira, v. 46, n. 3, p. 245-253, 2011.

SULTAN, S. E. Phenotypic plasticity in plants: a case study in ecological development. Evolution \& Development, v. 5, n. 1, p. 25-33, 2003

TAIZ, L.; ZEIGER, E. Fisiologia vegetal. Porto Alegre: Artmed, 2004. 719 p.

WEISS, E. A. Castor. In: WEISS, E. A. Oilseed crops. 2. ed. London: Blackwell Science, 2000. p. 13-51. 